\title{
ANALYSIS OF THE STRUCTURE AND PROPERTIES OF MATERIALS USED FOR LIGHTING COLUMNS
}

\author{
Agata DUDEK, Renata CABAN \\ Czestochowa University of Technology, Faculty of Production Engineering and Materials Technology, \\ Institute of Materials Engineering, Czestochowa, Poland, EU, dudek.agata@wip.pcz.pl
}

https://doi.org/10.37904/metal.2019.912

\begin{abstract}
The achievements of modern surface engineering can be applied in many areas. With modern engineering materials and manufacturing techniques, the comfort and safety of life of road users and other people present on the road have substantially improved. The road infrastructure includes street lighting, which uses modern lightweight materials from the group of non-ferrous materials or composites. Their surface is covered by various surface layers in order to improve functional properties of the finished part. This paper presents an analysis of the structure and functional properties of coatings used for street lighting columns, which have recently become very popular.
\end{abstract}

Keywords: Surface engineering, coatings, lighting columns

\section{INTRODUCTION}

Street lighting is now an integral part of every city and village. Light ensures road safety for all users, both those motorized and pedestrians. A well-lit roadway improves driving comfort, especially at night [1]. Lighting columns with passive safety features represent the elements of road traffic safety, whose task is to limit the consequences of road traffic incidents (accidents, collisions) [2,3]. Street lighting also increases the attractiveness and aesthetic values of the surroundings. Together with other elements of the city, it creates a coherent urban space and allows for bringing out the beauty of interesting or historic buildings. Complying with the requirements of the European standards is necessary for ensuring the safety and functionality of the public space. Modernization of street lighting should be based on the regulations contained in standards. In addition to lighting parameters, the standards also specify other aspects, such as environmental problems and the appearance of the installations. The appearance of the installation means primarily the aesthetics of the columns and light fittings and their location in relation to the surroundings. Aluminum alloys of the 6000 series (containing magnesium and silicon) are an excellent material for the production of lighting columns. These alloys have been used in a wide range of applications: construction, automotive components (including trucks), electronics, lighting, mining, chemical and shipbuilding industries [4]. Using the plastic processing of aluminum alloys in the production of tubular columns allows for obtaining column strength similar to that of steel columns. Lighting columns are made of aluminum pipes with specific diameters and wall thickness from $3 \mathrm{~mm}$ to $10 \mathrm{~mm}$ (depending on strength needed). The design of the column is uniform, which is achieved by the use of tube extrusion or rolling technology. Aluminum columns are subjected to anodizing, which consists in the electrochemical method of creating an oxide layer (coating) on the metal surface. Anodizing does not only protect the column from external effects for a long time, but it also gives the possibility of changing the colour of aluminum, which provides the lighting columns with exceptional decorative values.

\section{MATERIALS AND EXPERIMENTAL METHODS}

Two types of lighting columns, which have recently gained great popularity, were the materials used in the research. The geometrical parameters of the pipes from which the columns are made, i.e. external diameter, wall thickness and colour, are presented in Table 1. 
Table 1 Characteristics of the test material

\begin{tabular}{|c|c|c|c|}
\hline Column types & External diameter $(\mathrm{mm})$ & Wall thickness $(\mathrm{mm})$ & Colour \\
\hline 1 & 98 & 4.39 & silver \\
\hline 2 & 120 & 3.93 & gold \\
\hline
\end{tabular}

A number of tests were performed using the samples taken from the columns. The research methodology included:

- Microscopic examinations were performed using an Opta-Tech optical microscope and a Jeol JSM6610LV scanning electron microscope (SEM).

- Chemical composition analysis using a Jeol JSM6610LV scanning electron microscope (SEM) coupled with an Oxford EDS electron microprobe X-ray analyser,

- $\quad$ X-ray (XRD) measurements (analysis of the phase composition) using a Seifert 3003T/T X-ray diffractometer and the radiation originating from a tube with a cobalt anode $\left(\lambda_{c_{0}}=0.17902 \mathrm{~nm}\right) . \mathrm{XRD}$ measurements were performed in the 30-120 range of angles with an angular step of 0.2 and the exposure time of $4 \mathrm{~s}$. Computer software and the DHN PDS, PDF4 crystallographic database were used for the phase identification,

- $\quad$ Evaluation of coating adhesion by means of the scratch test using a RevetestXpress CSM Instrument device.

\section{RESULTS OF EXAMINATION}

Structural examinations were performed on metallographic sections etched with Keller's reagent using 200x magnifications. The results of the observations are presented in Figures 1 and $\mathbf{2}$.
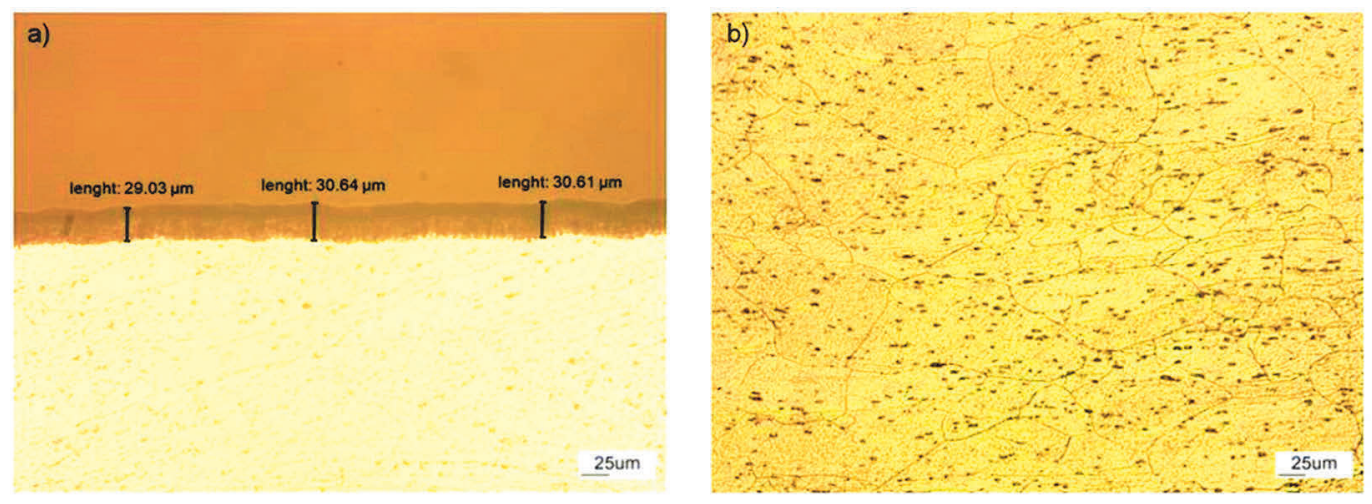

Figure 1 Microstructure - Columns 1: a) coating, b) core material (optical microscopy)
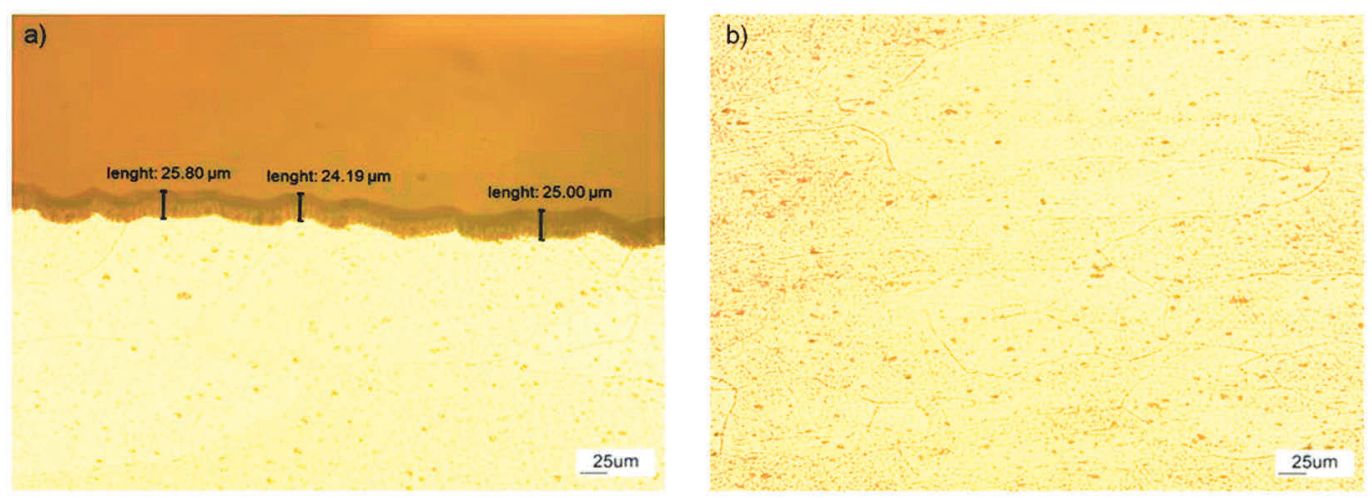

Figure 2 Microstructure - Columns 2: a) coating, b) core material (optical microscopy) 
A scanning microscope Jeol JSM6610LV was used to further analyse the functional properties of the coatings revealed on the surface of the columns. The microstructure photographs obtained for the materials studied are presented in Figure 3.
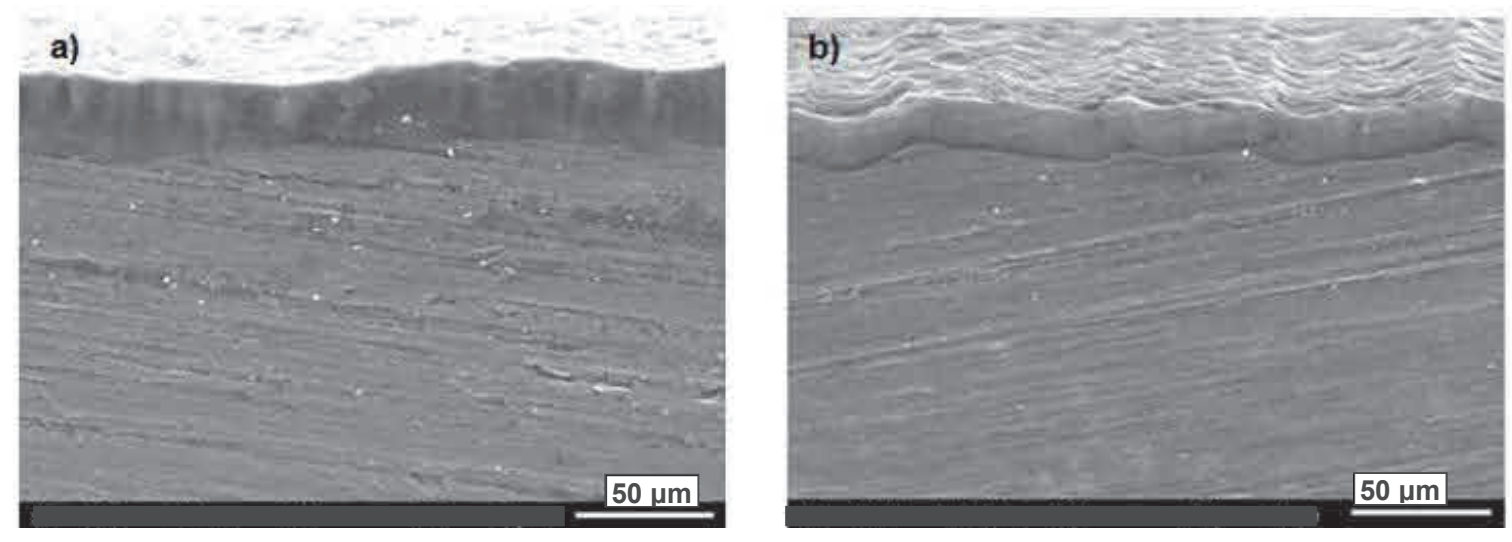

Figure 3 Scanning microscopy: a) columns 1, b) columns 2

Microscopic observations revealed coating of varying thickness on the column surface: ca. $30 \mu \mathrm{m}$ on the columns 1 and ca. $25 \mu \mathrm{m}$ on the columns 2. In the case of columns 2, a higher degree of development of the core material surface was observed. However, in both parts of the columns, the coatings were characterized by very good adhesion and homogeneity without noticeable defects such as cracks. The next stage of the study was the analysis of chemical composition using the EDS attachment of the scanning microscope Jeol JSM6610LV. The chemical composition of the core material and the anodized coatings were analysed. The distribution of elements in the materials tested is presented in Figures $\mathbf{4}$ and $\mathbf{5}$. Chemical analysis of the core material revealed the presence of aluminum, magnesium and silicon in case of columns 1 , whereas in columns 2 , there were only aluminum and silicon. The presence of oxygen and aluminum was found in chemical composition of coatings in both materials tested.
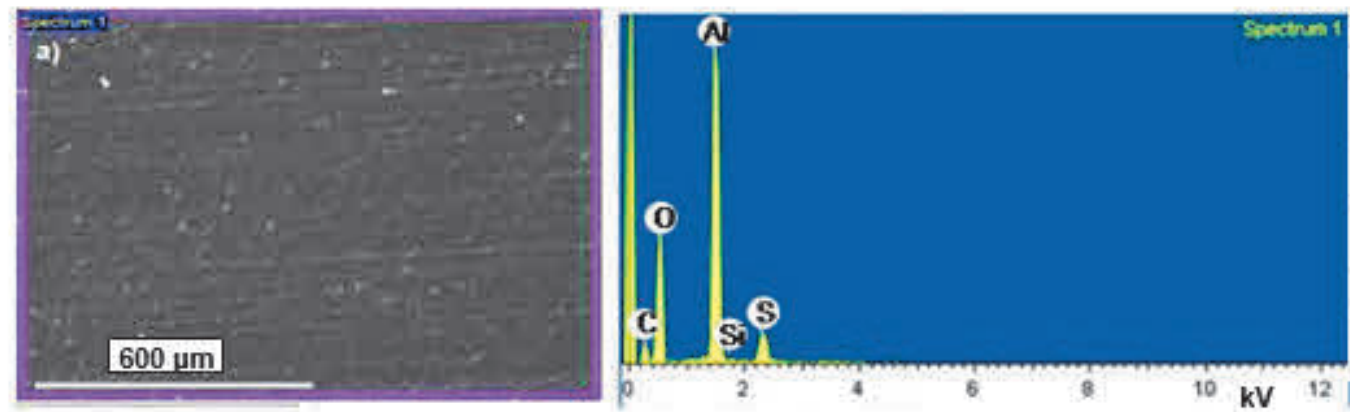

\begin{tabular}{|c|c|}
\hline Element & $\begin{array}{c}\text { Spectrum } \\
\text { (Wt\%) }\end{array}$ \\
\hline C & 22.44 \\
\hline 0 & 43.53 \\
\hline AI & 29.45 \\
\hline Si & 0.19 \\
\hline S & 4.39 \\
\hline
\end{tabular}
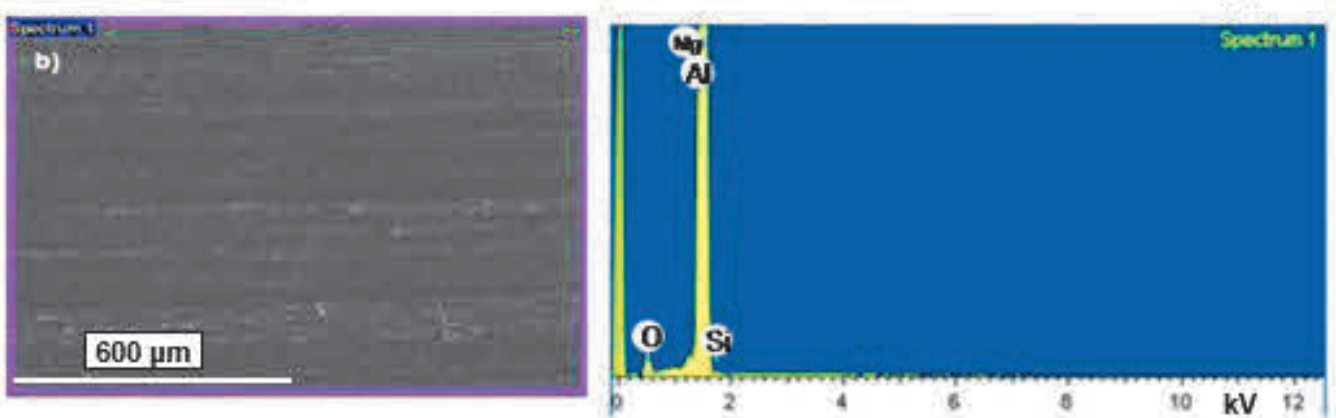

\begin{tabular}{|c|c|}
\hline Element & $\begin{array}{c}\text { Spectrum } \\
\text { (wt'\%) }\end{array}$ \\
\hline 0 & 4.87 \\
\hline $\mathrm{Mg}$ & 0.38 \\
\hline $\mathrm{Al}$ & 94.24 \\
\hline $\mathrm{Si}$ & 0.51 \\
\hline
\end{tabular}

Figure 4 Area and spectrum of EDX analysis for columns 1: a) coating, b) core material 

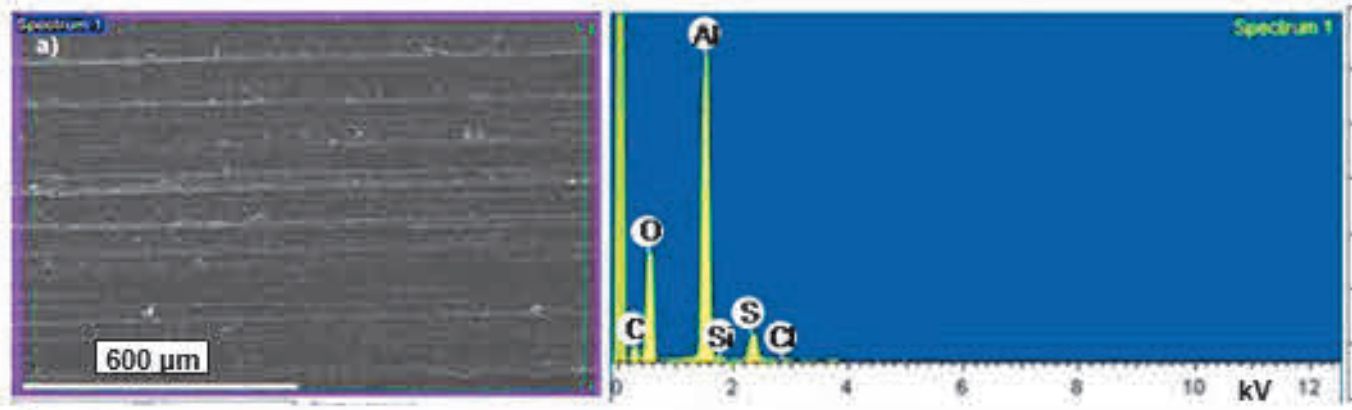

\begin{tabular}{|c|c|}
\hline Element & $\begin{array}{c}\text { Spectrum } \\
\text { (wrF) }\end{array}$ \\
\hline C & 22.75 \\
\hline$O$ & 42.56 \\
\hline AI & 30.06 \\
\hline SI & 0.43 \\
\hline S & 4.01 \\
\hline Cl & 0.19 \\
\hline
\end{tabular}
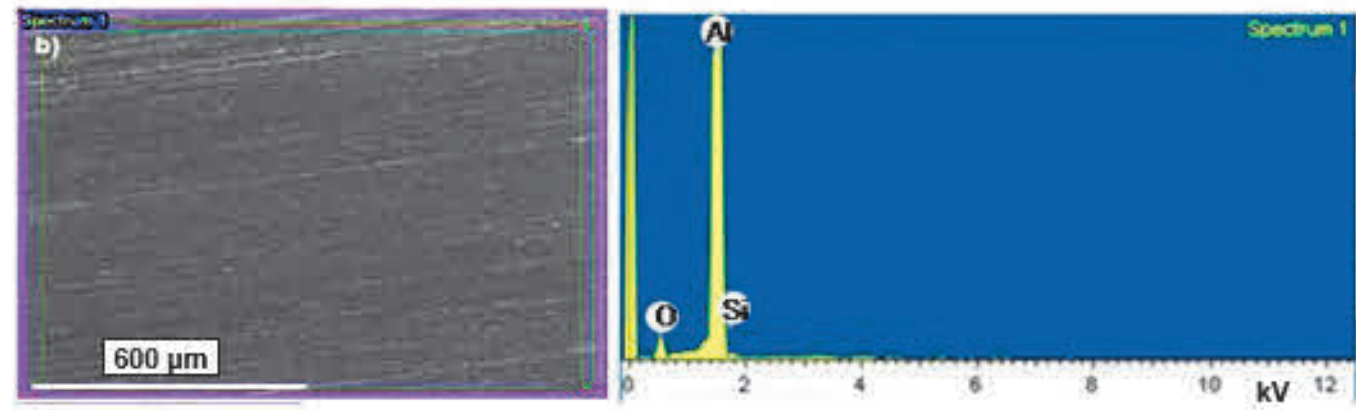

\begin{tabular}{|c|c|}
\hline Element & $\begin{array}{c}\text { Spectrum } \\
\text { (Mrk) }\end{array}$ \\
\hline 0 & 7.30 \\
\hline AI & 91.85 \\
\hline Si & 0.86 \\
\hline
\end{tabular}

Figure 5 Area and spectrum of EDX analysis for columns 2: a) coating, b) core material

A Seifert 3003T/T X-ray diffractometer with a cobalt lamp was used to further identify phase composition of the two series of samples. The results of X-ray measurements of the materials studied are presented in Figure 6. The analysis of diffractograms based on the standards from DHN-PDS and PDF4 databases confirmed the results of the EDX analysis that had showed presence of aluminum and $\mathrm{Al}_{2} \mathrm{O}_{3}$ aluminum oxides in the materials studied.

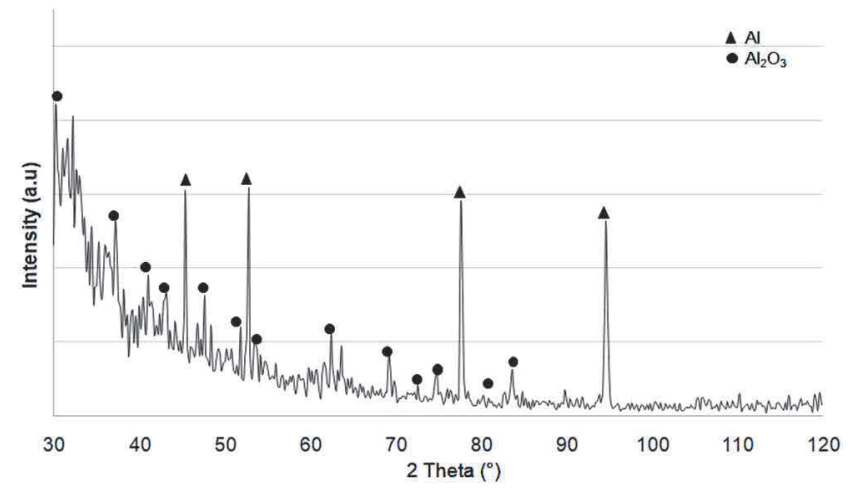

a)

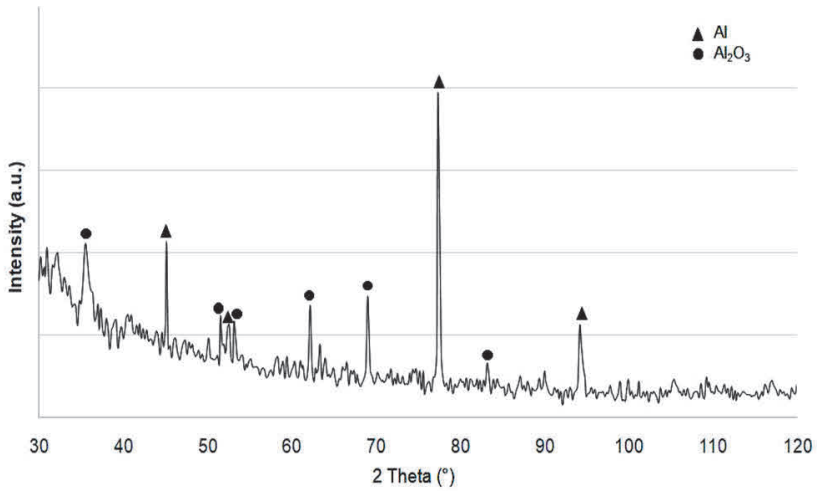

b)

Figure 6 X-ray diffractograms: a) columns 1, b) columns 2

The system of coating and core material was analysed in terms of coating adhesiveness by calculation of such parameters as frictional force, coefficient of friction, critical force of the coating decohesion. For this purpose, the scratch test was performed using a RevetestXpress CSM Instrument device. Automated microscopic observations allowed for the analysis of scratch lines along the entire length of force application. This observation made it possible to determine critical points during the test. Critical loads were determined by means of an optical microscope. Figure 7 shows graphs of test scratch data for individual test specimens and the appearance of scratch paths on coatings. 

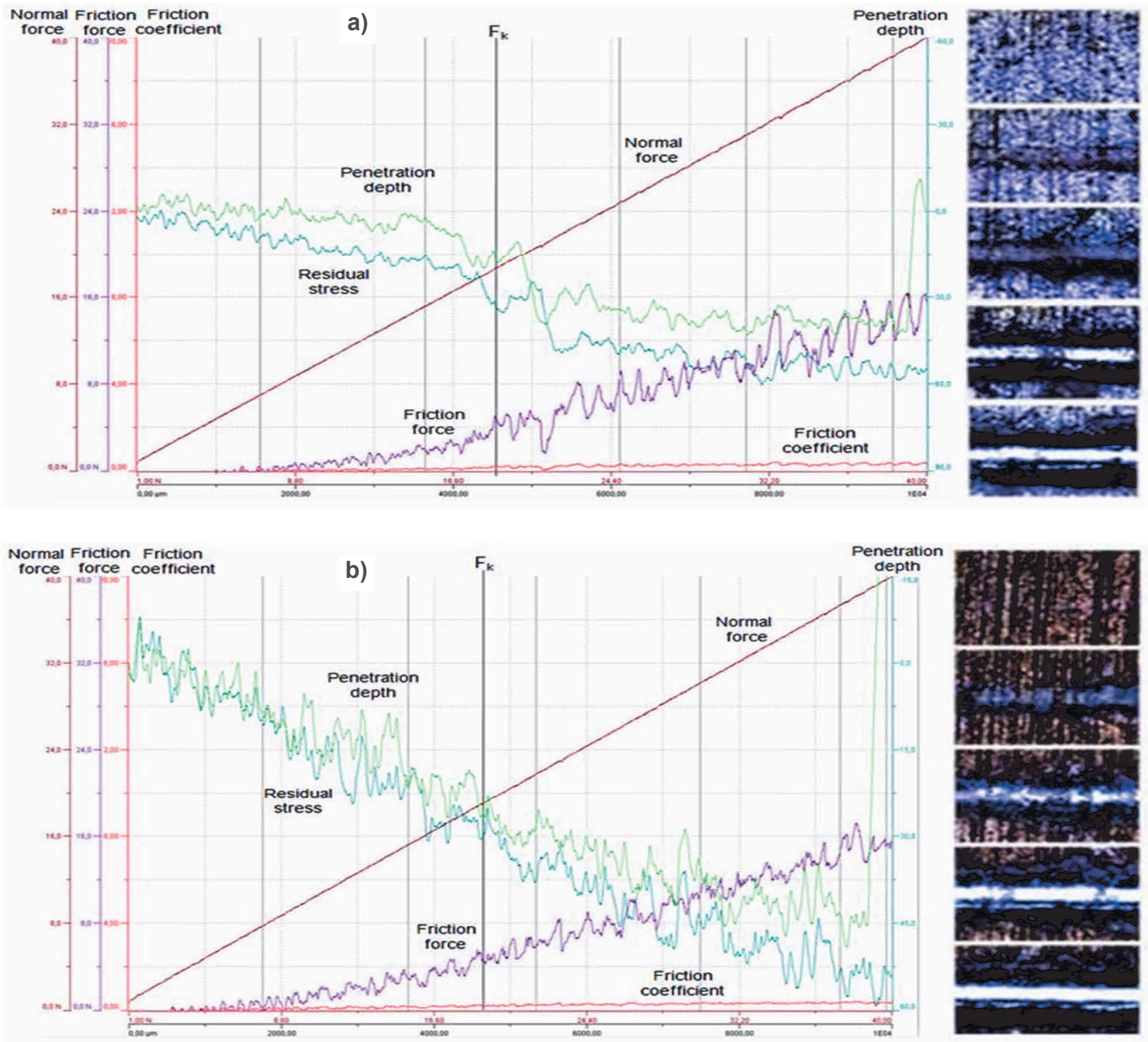

Figure 7 Graphs of test scratch data and scratch path for coatings: a) columns 1, b) columns 2

The analysis of the obtained images and geometric analysis of the width of the crack formed were carried out. Optical observation was performed to determine characteristic critical points during the test for which the coating was deformed or cracked. Microscopic examination and analysis of the diagrams presented in Figure 7 lead to the conclusion that the value of $F_{K}$ was a critical quantity determining the force at which the coating was detached from the core material. For columns 1 , the $F_{K}$ force was $18.34 \mathrm{~N}$, while for columns 2 , this was $19.7 \mathrm{~N}$.

\section{CONCLUSION}

Lighting columns made mainly of aluminum alloys due to the undisputed advantages of this material, which is successfully used every day in contact with various weather conditions such as rain, frost or high temperature. Tested anodized coatings produced by electrochemical method on two types of lighting columns consist of aluminum oxide. The coatings were integrally bonded to the substrate, there is no observed of exfoliation, chipping or delamination. Results, obtained in this investigation may be useful in wide areas of research and industry in similar cases like laser machining [5], material hardening [6], surface layer assessment [7-11]. In 
further investigation, more complex methods are planned to be employed as the advanced image analysis [12, $13]$ as well as resampling methods [14, 15] and design of experiment analysis [16, 17].

\section{REFERENCES}

[1] JIANG, Y., SHUO, L., GUAN, B., ZHAO, G. Cost effectiveness of new roadway lighting systems. Journal of Traffic and Transportation Engineering. 2015. vol. 2, pp. 158-166.

[2] MICHAŁEK, J. Bezpieczeństwo bierne słupów oświetleniowych. Drogownictwo. 2013. no. 7-8, pp. 249-255 [in Polish].

[3] ABDEL-NASSER, Y.A. Frontal crash simulation of vehicles against lighting columns using FEM. Alexandria Engineering Journal. 2013. vol. 52, pp. 295-299.

[4] AWANG, R., WANG, L., HE, C., LU, M., SUN, L. Studies on the sealing processes of corrosion resistant coatings formed on 2024 aluminum alloy with tartaric - sulfuric anodizing. Surface\&Coatings Technology. 2019. vol. 360, pp. 369-375.

[5] RADEK, N., SZCZOTOK, A., GADEK-MOSZCZAK, A., DWORNICKA, R., BRONCEK, J. and PIETRASZEK, J. The impact of laser processing parameters on the properties of electro-spark deposited coatings. Arch. Metall. Mater. 2018. vol. 63, pp.809-816.

[6] SZCZOTOK, A., RADEK, N. and DWORNICKA, R. Effect of the induction hardening on microstructures of the selected steels. In METAL 2018: 27th Int. Conf. Metallurgy and Materials. Ostrava: TANGER, 2018, pp. 12641269.

[7] DUDEK A., LISIECKA B. The effect of thermal oxidation of porous and non-porous titanium alloy. In METAL 2017: 26th International Conference on Metallurgy and Materials. Ostrava: TANGER, 2017. pp. 1234-1239.

[8] KMITA, T. and BARA, M. Surface oxide layers with an increased carbon content for applications in oil-less tribological systems. Chemical and Process Engineering. 2012. vol. 33, pp. 479-486.

[9] ULEWICZ, R. and NOVY, F.R. The influence of the surface condition on the fatigue properties of structural steel. Journal of the Balkan Tribological Association. 2016. vol. 22, pp. 1147-1155.

[10] BARA, M., KMITA, T. and KORZEKWA, J. Microstructure and properties of composite coatings obtained on aluminum alloys. Arch. Metall. Mater. 2016. vol. 61, pp. 1107-1112.

[11] BARA, M., NIEDZWIEDZ, M. and SKONECZNY, W. Influence of anodizing parameters on surface morphology and surface-free energy of $\mathrm{Al}_{2} \mathrm{O}_{3}$ layers produced on EN AW-5251 alloy. Materials. 2019. vol. 12, art. 695.

[12] GADEK-MOSZCZAK, A., WOJNAR, L. Objective, quantitative and automatic $x$-ray image analysis of the bone regenerate in the ilizarov method. In ECS10: The 10th European Congress of Stereology and Image Analysis. Milan: ISS. 2009. pp.453-458.

[13] WOJNAR, L., GADEK-MOSZCZAK A. and PIETRASZEK J. On the role of histomorphometric (stereological) microstructure parameters in the prediction of vertebrae compression strength. Image Analysis and Stereology. 2019. vol. 38, pp.63-73.

[14] GADEK-MOSZCZAK, A., PIETRASZEK, J., JASIEWICZ, B., SIKORSKA, S. and WOJNAR, L. The bootstrap approach to the comparison of two methods applied to the evaluation of the growth index in the analysis of the digital x-ray image of a bone regenerate. New Trends in Comput. Collective Intell. 2015. vol. 572, pp.127-136.

[15] PIETRASZEK, J., KOLOMYCKI, M., SZCZOTOK, A., DWORNICKA, R., 2016. The fuzzy approach to assessment of ANOVA results. In ICCCI 2016: Conf. on Comp. Collective Intell. Seoul: Springer, pp. 260-268.

[16] SKRZYPCZAK-PIETRASZEK, E., REISS, K., ZMUDZKI, P. and PIETRASZEK, J. Enhanced accumulation of harpagide and 8-O-acetyl-harpagide in Melittismelissophyllum L. agitated shoot cultures analyzed by UPLCMS/MS. PLOS ONE. 2018. vol.13, e0202556.

[17] SKRZYPCZAK-PIETRASZEK E., PISKA, K. and PIETRASZEK, J. Enhanced production of the pharmaceutically important polyphenolic compounds in Vitexagnuscastus L. shoot cultures by precursor feeding strategy.

Enginnering in Life Sciences. 2018. vol. 18, pp. 287-297. 